\title{
The influence of service quality on tourist loyalty: a case of electric train services
}

\section{Noraihan Mohamad}

School of Hospitality and Creative Arts, Management and Science University, University Drive, Off Persiaran Olahraga, 40100, Shah Alam Selangor, Malaysia Email: noraihan_mohamad@msu.edu.my

\begin{abstract}
Electric train services (ETS) is the first high-speed intercity train system in Malaysia that significantly contributed to the nation's economy and tourism industry. This study examined the impacts of service quality of ETS towards tourist satisfaction and loyalty. Data were generated through a self-administered survey. A total of 360 responses from tourists who travelled to and from Kuala Lumpur Sentral and Padang Besar, Malaysia were collected and were subjected to technical analysis of partial least square-structural equation modelling (PLS-SEM). This study demonstrated the significant impact of service quality towards tourist satisfaction and loyalty toward ETS. Finally, valuable recommendations are presented.
\end{abstract}

Keywords: electric train services; ETS; tourist loyalty; tourist satisfaction; functional service; technical service; safety.

Reference to this paper should be made as follows: Mohamad, N. (2022) 'The influence of service quality on tourist loyalty: a case of electric train services', Int. J. Knowledge Management in Tourism and Hospitality, Vol. 2, No. 4, pp.315-330.

Biographical notes: Noraihan Mohamad is a Senior Lecturer at the School of Hospitality and Creative Arts, Management and Science University (MSU). She received Master of Science and $\mathrm{PhD}$ in Media Management from Universiti Utara Malaysia (UUM). Her research interests are on the media management in the context of society, businesses, and consumers. Her scope of expertise is Malaysian mass media and new media, media and technology (including social networking), and tourism marketing. She presented numerous papers at national and international conferences and contributed articles in journals and chapters in books on media and tourism. Her current contribution to Malaysia's Government is on developing a Malaysian National Unity Index.

\section{Introduction}

Public transportation is important basic infrastructure as it can deliver efficient services to citizens, improve development processes and also minimise congestion that could lead to carbon emissions (Mat et al., 2019). Having said that, public transportation has been identified as a key driver of the economy for the country and highlighted as a significant sector in the tourism industry to providing better experience to tourists during their 
journey to the desired destination (Willy et al., 2018; Mat et al., 2019; Hashim et al., 2019). Public transport such as railway services are part of public transport that significantly help in reducing traffic congestion especially during peak hours or festive seasons. Besides helping to reduce stop-start driving and fuel consumption, it also saves passengers' time and energy.

Service quality is an essential aspect to consider in public transport to ensure its reliability and comfort for public usage, whereby it should also be environment friendly. The Malaysian railways are also facing challenges in improving their services and reliability to enhance the competitiveness in the public transportation sector including cleanliness, comfortability, punctuality, frequencies and responsiveness of personnel (Sahrir et al., 2018). Mat et al. (2019) mention that the common problems related to public transport include reliability, responsiveness and tangibility. A study by Machado-Leon et al. (2017) emphasised the role of availability, connectivity, knowledge, time, comfort and reliability in quality of service as factors influencing people's decision in choosing public transport. Besides, effective services and accessible railway network to a tourist destination also recognised as important predictors to develop tourists' satisfaction and their intention to revisit to the destination using the same mode of transportation (Anjali and Prita, 2018; Willy et al., 2018). The other important factors that are always considered for choosing the railway transportation include credibility of personnel, safety and security, cleanliness, convenience, timeliness, schedules, physical mobility and accessibility (Yusoff et al., 2019; Mat et al., 2019).

Even though research on the effectiveness of Malaysian public transport has been previously performed by scholars, research on ETS is still at a preliminary stage. Hence, it is important to highlight the efficacy of ETS from different perspectives. Since ETS is a relatively new public transport system in Malaysia, limited literature is available on the elements of service quality and passengers' loyalty toward ETS (Mat et al., 2019). Moreover, Willy et al. (2018) mentioned that limited data have been published on the perspectives of railway passengers, especially in the Asian countries. Most of the previous studies focused on light rapid transit (LRT), commuter, taxi, bus and e-hailing (Zakaria et al., 2010; Ojo et al., 2014; Sahrir et al., 2018). As railway service quality has been identified to hold significant effects on passengers' perception and behaviour, this study aims to investigate the effects of service quality components of ETS consisting of functional service quality, technical service quality and safety on tourist satisfaction together with loyalty.

\section{Literature review}

\subsection{Tourism and railway transportation in Malaysia}

The tourism industry in Malaysia is the fifth-largest industry after the oil and gas industry and the palm oil industry which significantly contribute to the nation's economy and foreign trade income (The Star, 2019; Tourism Malaysia, 2020). Since the railway transportation is a significant sub-sector of the tourism industry, it is considered as a major feature of tourism especially in creating an effective travel intention (Willy et al., 2018). The rail network is of particular importance due to its low-cost, high-security and convenient journey. Due to that, the local tourist spots have also been highlighted and embedded into the railway system (Görçün, 2018; Hashim et al., 2019). Having said that, 
the day-to-day development of monorail and rail tracks development in the forest and mountainous areas alongside the use of internal train attraction represents the high demands and importance of rail transport in the development of tourism. ETS is a modern heavy rail approach by KTMB as it runs fully on electrified tracks with older trains. This high-speed train was first launched in 2010 for the Kuala Lumpur-Ipoh route for an approximate travel time of between 2.5 and 3 hours depending on the form of train service (KTMB History, 2018). ETS is useful in both the tourism industry and transportation sector. ETS may offer the best option for medium and long-distance travelling compared to the alternative public transports particularly in the field of domestic tourism.

\subsection{Tourist loyalty}

Customer loyalty is a key factor in explaining the long-term relationship between customer and businesses (Morgan and Hunt, 1994). Customer loyalty is proven by repeat purchases, purchasing frequency, recommend to other potential customers, price tolerance and positive review. Therefore, loyalty is defined as commitment to rebuy or repatronise a preferred product or service consistently in the future, leading to repetitive same-brand or the same brand set purchasing (Bahtiar and Zaini, 2014; Mgiba and Madela, 2020; Mohamad, 2020). Customer loyalty towards public transport is associated with their perceptions on value for money, onboard safety, cleanliness, convenience, flexibility and also the brand image of the services. Shifting from privately owned vehicles to public transport such as buses, trains and taxis have several advantages including decreased road congestion, reduced environmental pollutions and controlled environmental issues (global warming and climate change) by encouraging energy saving (Shiaw et al., 2019). Previous studies stated that tourists will heavily rely on public transportation if it enables them to reach their destination on-time with comfortable services and facilities, efficient safety and security system, together with efficient communication tools (Fu et al., 2017; Görçün, 2018; Hashim et al., 2019; Ibrahim et al., 2020).

Since ETS is the main high-speed railway transportation for long journey in Malaysia, there are various support programs implemented by the authorities such as KTMB and the Ministry of Tourism, Arts and Cultures (MOTAC) to develop loyalty among tourists. One of that is KTMB Integrated Ticketing System (KITS) where tourists can buy ticket at low fares for ETS, KTM Intercity and KTM Commuter services through the KTMB Mobile application (The Star, 2013). Besides, KTMB persistently updating their daily activities in social media including maintenance activities, schedule and in-train services to gain passengers' trust by creating positive perceptions and expectation, thus influencing their intention to use ETS (Putri et al., 2018; Mohamad, 2020).

\subsection{Service quality}

Service quality is always the main issue when it comes to public transport (Ramya et al., 2019; Kukanja and Planinc, 2020). Service qualities refer to the gap between customers' perception and expectation of the company's service performance (Parasuraman et al., 1988). The SERVQUAL is a popular instrument and has been tested in many service 
qualities studies. It includes the dimensions of tangibility, reliability, responsiveness, assurance and empathy (Parasuraman et al., 1988). Nevertheless, it was extended by many previous studies to assess the quality of railway services by adding new factors. Cavana et al. (2007) assessed the quality of passenger rail services in Wellington, New Zealand by testing factors of connectivity, comfort and convenience. Geetika and Shefali (2010) highlighted the importance of the availability of transit service, service monitoring, travel time, safety and security, and maintenance and construction activity in measuring railway service quality. Moreover, de Oña et al. (2016) suggested that measuring the quality of service is important to identify the level of safety, cleanliness, comfort, information provided and reliability of personnel. Besides that, Yilmaz and Ari (2016) focused on the effects of technical service quality, functional service quality and corporate image in measuring passengers' satisfaction and loyalty towards high-speed rail service in Turkey. While study by Wang et al. (2020) investigated the effects of functional service quality, technical service quality, comfort and cleanliness together with service planning and reliability on passengers' satisfaction and reuse intention towards urban rail transit in Tianjin, China. In short, the other vital factors that have been studied in previous studies to determine the quality service of railway public transport include availability, accessibility, information, time, comfort, waiting time, crowdedness, fair and safety (Isikli et al., 2017; Machado-Leon et al., 2017).

According to Parasuraman et al. (1988), service quality is a significant factor influencing customer satisfaction and loyalty. The level of quality service can be measured by the levels of customer satisfaction and loyalty (Ramya et al., 2019). In the context of public transport, the quality of service was identified as the main component to attract people's intention (de Oña et al., 2016). Mat et al. (2019) added that beside safety, the dimensions of service quality such as tangibility, reliability, responsiveness, assurance and empathy are important factors that can affect passengers' satisfaction towards ETS. In addition, Wang et al. (2020) indicate that customer satisfaction and reuse intention of urban rail transportation strongly rely on the dimensions of service quality. This study refers service quality as functional service quality, technical service quality and safety as indicators of tourist satisfaction and loyalty towards ETS.

\subsection{Functional quality service}

Functional quality service explains the process of service delivery from service provider to the end consumers through an appropriate attitude and interaction (Yilmaz and Ari, 2016; Nasrul, 2020). Although functional quality service can be assessed in a highly subjective manner, it is related to passenger's expectation towards the facilities and services provided at the railway stations and in- train. For instance, comfortable waiting area which can accommodate many people at any one time, accessibility of facilities, standard operating procedures applied, effective security system, police post and adequate parking area including pick-up and drop-off area (Oyedele, 2018). Meanwhile, passenger's expectation towards in-train facilities includes coaching facilities, thermal comfort, safety, and internet accessibility along the journey (Masirin, et al., 2017; Wang et al., 2020). It is essential to provide facilities such as wireless internet connection and electric power socket onboard due to people nowadays needs to stay connected to the internet as it is a part of life either for personal or business purposes (Karim et al., 2012). The other in-train facilities expected by passengers include special space for luggage, facilities for disabled passengers and closed-circuit television (CCTV) systems, good air 
conditioner temperature, cleanliness and a nice environment (Yilmaz and Ari, 2016; Yusoff et al., 2019). Moreover, ETS also expected to provide LED screen playing appropriate movies or documentaries along the journey. Prior studies indicated that as the railway functional service quality increase, customer satisfaction and their perception towards the corporate image of the service provider will also increase (Yilmaz and Ari, 2016; Anjali and Prita, 2018; Willy et al., 2018). By taking this in mind, the following hypothesis was proposed:

H1 Functional service quality significantly influences tourist satisfaction towards ETS $\left(\mathrm{P}_{14}\right)$.

\subsection{Technical service quality}

Technical quality refers to the standards of the service offered by the business to the customers (Faizan et al., 2017; Khaleel and Sayah, 2020). Technical service quality can be measured based on management perception and service procedure, how service is provided and what the customers receive (Yilmaz and Ari, 2016). It can also be referred to equipment, train maintenances, railway operations, punctuality and booking system (Wang et al., 2020). Technical service quality such as delays and punctuality are a major reason for public transportations to face criticism (Tripathi and Borrion, 2016; Olsson, 2020). Waiting can lead to negative emotions such as frustration, anger, and anxiety among customers. Usually, long-distance journeys have reduced punctuality than short journeys due to external disruptions. Nowadays, online ticket booking, or e-ticketing in railway services has become important. The ticketing system flow are expected to be more reliable, convenient, faster, and effortless (Ghosal et al., 2015). The ticketing system also should involve smartcard technology to accommodate the use of credit cards, security passes and public transit tickets for a cashless global economy (Najafipour et al., 2019). Due to that, KTMB has develop e-ticketing system through their official website and mobile application (KITS) for passengers to check the availability of ticket and destinations apart from ticket purchasing. Previous literature found that technical service quality is a critical factor in determining customer satisfaction and loyalty towards railway transportation (Yilmaz and Ari, 2016; Vu et al., 2020). Thus, the following hypothesis was proposed:

H2 Technical service quality significantly influences tourist satisfaction towards ETS $\left(\mathrm{P}_{24}\right)$.

\subsection{Safety}

Safety is relative freedom from damage, fear or possibility of hurt, injury or loss to individuals and/or properties, whether caused deliberately or by accident (Hamid et al., 2015). Čičmancová (2013) defined safety as a property of a network that in no way endangers either individuals or its environment. In transportation services, the safety factor is a vital aspect that needs to be considered by the service provider as it always the main factor considered by the passengers. From the customer's perspective, safety means social security and is a prerequisite in tourists' decision making before they start their journey. They will only choose a particular mode of transportation only if it is free from danger, harm, and fear (Geetika and Shefali, 2010; Hamid et al., 2015). Safety issues in 
railway transportation are related to the management procedures, government legislation and the advancement of technology (Hernik and Mazur, 2018; Yusoff et al., 2019). Moreover, the most important issue in railway transportation safety is to avoid accidents caused by human errors, unexpected accidents and various combinations of unfavourable conditions that can negatively affect the safety of various elements or the entire railway network (Nordin et al., 2017; Wang et al., 2020). Hernik and Mazur (2018) added that railway transportation is one of the safest transportations for travelling purposes. Similarly, safety and security factor were identified to be the best predictor of tourists' satisfaction and loyalty towards railway transportation (Mat et al., 2019; Shiaw et al., 2019). Hence, KTMB persistent in attempting to guarantee on-site safety for passengers to continue using ETS (Nordin et al., 2017; Murugan, 2020). Therefore, the following hypothesis was formed:

H3 Safety significantly influences tourist satisfaction towards ETS $\left(\mathrm{P}_{34}\right)$.

\subsection{Tourist satisfaction}

Satisfaction is a component of attitude that persistently predicts loyalty (Mohamad, 2020; Basari and Shamsudin, 2020). Customer satisfaction is a psychological reaction that refers to customers' emotion and affective attitude towards the product, services and service provider (Sulphey and George, 2017; Basari and Shamsudin, 2020). Customer satisfaction refers to customer's evaluation towards products or services to perform as expected (Kim et al., 2015; Sulphey and George, 2017). Prior studies stated that various potential factors can affect customer satisfaction towards a product, service, brand or business. For instance, the factors include social, psychology, personnel, facilities, knowledge, experience, product alternative, market trend, promotion, a medium of communication, etc. (Kim et al., 2015; Mohamad, 2020). It has been proven that customer satisfaction would gradually lead to customer trust and loyalty to an organisation (Aida et al., 2020). Based on previous results, customer satisfaction is the bridge between the quality of service and intention to reuse (Wang et al., 2020). Furthermore, de Oña et al. (2016) asserted that positive customer satisfaction is directly linked to customers' intention to reuse railway transportation. Moreover, previous studies have consistently indicated that satisfaction is a significant predictor towards passengers' loyalty to railway transportation including ETS (Yilmaz and Ari, 2016; Mat et al., 2019; Wang et al., 2020). By taking this in mind, the following hypothesis was proposed:

H4 Tourist satisfaction significantly influence tourist loyalty towards ETS $\left(\mathrm{P}_{45}\right)$.

\subsection{Research model and hypotheses}

Figure 1 illustrates the research model developed based on the arguments provided in prior sections. The model indicated the influences of exogenous variables which are functional service quality, technical service quality, safety and tourist satisfaction towards the endogenous variable of tourist loyalty. 
Figure 1 Research model

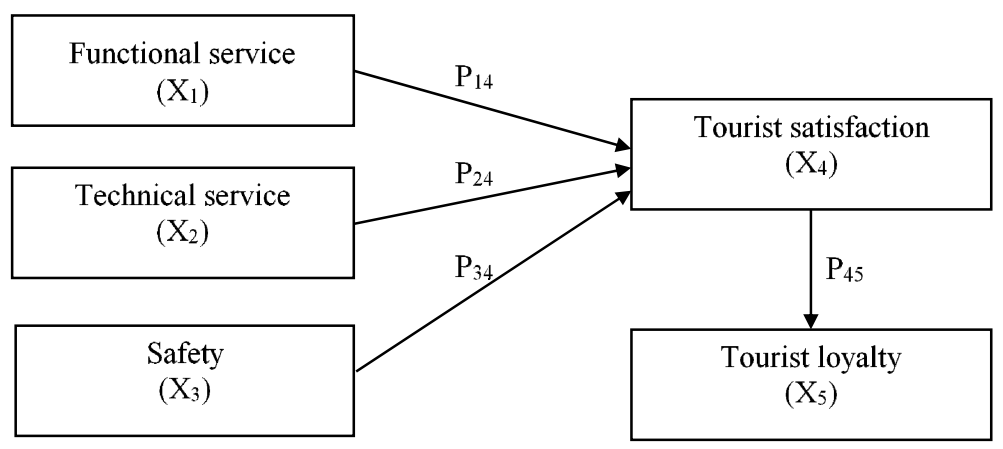

\section{Methodology}

\subsection{Research design and sampling}

The cross-sectional design was incorporated in this study to identify the perceptions of the respondents towards ETS services. Based on the convenience sampling technique, a total of 450 self-administered questionnaires were distributed to tourist who were travelling to and fro Kuala Lumpur Sentral Station to Padang Besar station. However, only 360 complete responses from respondents were assessed in this study. This sample size meets the threshold for two statistical sampling procedures. First, based on PLS-SEM technique, each structural path in the PLS research model needs to be multiplied by 10 (Hair et al., 2014). Thus, the minimum number of respondents needed for this study was 40 (4 structural paths $\times 10)$. Second, for a large or unknown population, the minimum appropriate sample size is 100 to 200 (Hair et al., 2006). Thus, the sample size was considered acceptable and valid for further analysis.

\subsection{Measurement and data analysis}

Section A of research instrument comprises the profile demographic of respondents and questions related to respondent's perception towards ETS. Section B addresses the functional service, technical service, safety, tourist satisfaction and tourist loyalty construct. These constructs were measured using a five-point Likert scale $(1=$ strongly disagree to $5=$ strongly agree). Construct tourist loyalty was measured by using five items adapted from Wang et al. (2020). Eight items were retrieved from Yilmaz and Ari (2016), where four items belonged to functional service quality and the other four items of technical service quality. Six items for construct safety and seven items for construct tourist satisfaction were adapted from Mat et al. (2019). The IBM Statistical Package for Social Sciences (SPSS) version 22 was employed to complete the descriptive analyses. To test the research hypotheses, an inferential analysis was implemented using the SmartPLS software to perform the PLS-SEM technique (Hair et al., 2014). PLS-SEM technique was employed to evaluate the reflective measurement model and structural model. 


\section{Results}

\subsection{Respondent's profile demographic}

Of the total 360 respondents who participated in this study, $56.9 \%$ of the respondents were females compared to $43.1 \%$ males. Most of the respondents were Malaysians $(93.1 \%)$ and only $6.9 \%$ of respondents comprised of tourists from Brunei, Singapore, Indonesia and Australia. It is also demonstrated that the most attracted factor to use ETS was affected by comfort and cleanliness of the ETS (62.8\%). Most of respondents were found used ETS for holiday and vacation (50.8\%), to visit family (32.2\%), friends $(20.6 \%)$ and business purposes $(20.8 \%)$. Besides that, analysis on sources of information revealed that majority of the respondents gained information regarding ETS through KTMB's official website $(81.1 \%)$, followed by friends' referrals $(46.4 \%)$, social media $(45.8 \%)$, family $(33.9 \%)$ and printed media such as newspaper, magazine and brochure $(12.7 \%)$. The descriptive analysis on tourist's satisfaction towards ETS indicated that majority of the respondents were satisfied with the ETS service provided by KTMB $(93.3 \%)$ and have a strong intention to reusing ETS for their next trip (81.1\%). However, only $18.9 \%$ of respondents were not interested in choosing ETS for their next trip due to factors such as cost, schedule flexibility and accessibility of ETS destinations. Moreover, respondents who are always travelling with family prefer to use private vehicles as it is more comfortable and flexible.

\subsection{Reflective measurement model evaluation}

Result exhibited in Table 1 indicated the reflective construct met the criteria for reflective measurement model assessment. The analysis specifically revealed that the Cronbach alpha $(\alpha)$, composite reliability (CR), factor loading $(\lambda)$ and AVE values for all construct were well-above the thresholds. Meanwhile, items with factor loading values under the thresholds were maintained since the construct where they belong to had already achieved the CR and AVE value (Hair et al., 2014; Garson, 2016).

The evaluation of discriminant validity based on cross-loading value proved that the discriminant validity was obtained as all indicators were loaded in its appropriate construct. Table 2 and Table 3 illustrate the discriminant validity evaluation based on Fornell-Larcker criteria and the Heterotrait-Monotrait (HTMT) ratio. Fornell-Larcker criteria were achieved when each construct achieved AVE square root value greater than the correlation coefficient value $(\sqrt{ } \mathrm{AVE}>\mathrm{r})$. This value indicates that the construct is unique and different from the others. While the HTMT criteria confirm whether the construct is unique based on the value of correlation coefficient between constructs lesser than 0.90 (HTMT.90 < 0.90) (Hair et al., 2014; Garson, 2016).

\subsection{Structural model evaluation}

The measurement of structural model was based on the evaluation of several values namely, the variance inflation factor (VIF $<5$ ), path coefficient $(\beta)$, standard error $(\mathrm{SE})$, $t$-value $(t>1.96)$, $p$-value $(p<0.05)$ and confidence interval $(C I)$ value at $95 \%$. The VIF value indicated that the predictive variables have no collinearity issue since the VIF value for each exogenous construct is less than 5 toward the endogenous construct. Table 4 
presents the highest value is shows by relationship between construct functional service quality and tourist satisfaction $(\mathrm{VIF}=1.924)$.

Table 1 Reflective measurement model evaluation

\begin{tabular}{|c|c|c|c|c|c|c|c|}
\hline Constructs & Items & $\begin{array}{c}\lambda \\
(>0.708)\end{array}$ & $\begin{array}{c}I R \\
(>0.501)\end{array}$ & $\begin{array}{c}(\alpha) \\
(>0.7)\end{array}$ & $\begin{array}{c}C R \\
(>0.7)\end{array}$ & $\begin{array}{c}A V E \\
(>0.5)\end{array}$ & $\begin{array}{l}\text { Discriminant } \\
\text { validity }\end{array}$ \\
\hline \multirow{4}{*}{$\begin{array}{l}\text { Functional } \\
\text { service } \\
\text { quality }\end{array}$} & FSQ_1 & 0.788 & 0.621 & \multirow[t]{4}{*}{0.810} & \multirow[t]{4}{*}{0.875} & \multirow[t]{4}{*}{0.637} & \multirow[t]{4}{*}{ Yes } \\
\hline & FSQ_2 & 0.81 & 0.656 & & & & \\
\hline & FSQ_3 & 0.749 & 0.561 & & & & \\
\hline & FSQ_4 & 0.843 & 0.711 & & & & \\
\hline \multirow[t]{6}{*}{ Safety } & S_1 & 0.714 & 0.510 & \multirow[t]{6}{*}{0.814} & \multirow[t]{6}{*}{0.864} & \multirow[t]{6}{*}{0.526} & \multirow[t]{6}{*}{ Yes } \\
\hline & S_2 & 0.721 & 0.520 & & & & \\
\hline & S_3 & 0.714 & 0.510 & & & & \\
\hline & S_4 & 0.716 & 0.513 & & & & \\
\hline & S_5 & 0.788 & 0.621 & & & & \\
\hline & S_6 & 0.713 & 0.508 & & & & \\
\hline \multirow{4}{*}{$\begin{array}{l}\text { Technical } \\
\text { service } \\
\text { quality }\end{array}$} & TSQ_1 & 0.798 & 0.637 & \multirow[t]{4}{*}{0.805} & \multirow[t]{4}{*}{0.873} & \multirow[t]{4}{*}{0.631} & \multirow[t]{4}{*}{ Yes } \\
\hline & TSQ_2 & 0.757 & 0.573 & & & & \\
\hline & TSQ_3 & 0.834 & 0.696 & & & & \\
\hline & TSQ_4 & 0.787 & 0.619 & & & & \\
\hline \multirow{7}{*}{$\begin{array}{l}\text { Tourist } \\
\text { satisfaction }\end{array}$} & SAT_1 & 0.717 & 0.514 & \multirow[t]{7}{*}{0.871} & \multirow[t]{7}{*}{0.901} & \multirow[t]{7}{*}{0.567} & \multirow[t]{7}{*}{ Yes } \\
\hline & SAT_2 & 0.817 & 0.667 & & & & \\
\hline & SAT_3 & 0.712 & 0.507 & & & & \\
\hline & SAT_4 & 0.843 & 0.711 & & & & \\
\hline & SAT_5 & 0.731 & 0.534 & & & & \\
\hline & SAT_6 & 0.719 & 0.517 & & & & \\
\hline & SAT_7 & 0.777 & 0.604 & & & & \\
\hline \multirow{5}{*}{$\begin{array}{l}\text { Tourist } \\
\text { loyalty }\end{array}$} & TL_1 & 0.778 & 0.605 & \multirow[t]{5}{*}{0.914} & \multirow[t]{5}{*}{0.936} & \multirow[t]{5}{*}{0.745} & \multirow[t]{5}{*}{ Yes } \\
\hline & TL_2 & 0.86 & 0.740 & & & & \\
\hline & TL_3 & 0.898 & 0.806 & & & & \\
\hline & TL_4 & 0.868 & 0.753 & & & & \\
\hline & TL_5 & 0.906 & 0.821 & & & & \\
\hline
\end{tabular}

Table 2 Fornell-Larcker criteria

\begin{tabular}{lccccc}
\hline Constructs & 1 & 2 & 3 & 4 & 5 \\
\hline Functional service quality (1) & 0.798 & & & & \\
Safety (2) & 0.604 & 0.718 & & & \\
Technical service quality (3) & 0.633 & 0.598 & 0.795 & & \\
Tourist loyalty (4) & 0.631 & 0.575 & 0.682 & 0.863 & \\
Tourist satisfaction (5) & 0.641 & 0.670 & 0.716 & 0.727 & 0.753 \\
\hline
\end{tabular}

Notes: The values in bold are AVE square root values. 
Table 3 HTMT ratio

\begin{tabular}{lccccc}
\hline Constructs & 1 & 2 & 3 & 4 & 5 \\
\hline Functional service quality (1) & & & & & \\
Safety (2) & 0.725 & & & & \\
Technical service quality (3) & 0.770 & 0.723 & & & \\
Tourist loyalty (4) & 0.725 & 0.655 & 0.788 & & \\
Tourist satisfaction (5) & 0.753 & 0.778 & 0.846 & 0.808 & \\
\hline
\end{tabular}

Notes: HTMT.90<0.90.

Table 4 Construct collinearity evaluation

\begin{tabular}{lcllc}
\hline Tourist satisfaction & & \multicolumn{2}{c}{ Tourist loyalty } \\
\cline { 1 - 2 } \cline { 5 - 6 } Constructs & VIF & & Construct & VIF \\
\hline Functional service & 1.924 & & Tourist satisfaction & 1.000 \\
Safety & 1.794 & & & \\
Technical service & 1.901 & & & \\
\hline
\end{tabular}

Notes: VIF $<5=$ No collinearity.

The significant evaluation was carried out through the bootstrapping operation $(5,000$ samples) based on the statistical t-value. The two-tailed hypothesis explains whether the parameter is significant at $0.05(\mathrm{p}<0.05)$ (Hair et al., 2014). The results indicated that all four predictor constructs significantly affect the endogenous constructs. Firstly, the functional service quality has a significant influence on tourist satisfaction towards ETS $(\beta=0.198, \mathrm{t}=4.102, \mathrm{p}<0.05, \mathrm{CI}[0.104,0.293])$. Previous literature posited that facilities provided on the train such as information, food area, internet connection, electric connectivity, LED screen, CCTV, cleanliness, air conditioner temperature and the good environment will enhance passengers' satisfaction level (Karim et al., 2012; Yilmaz and Ari, 2016; Yusoff et al., 2019). Moreover, passengers' satisfaction is also influenced by the basic facilities at the railway stations such as toilet, bathroom, prayer room, receptionist counter, food court, safety and security system, sufficient parking area and comfortable waiting area (Masirin et al., 2017; Oyedele, 2018; Wang et al., 2020). Hence, Hypothesis $1\left(\mathrm{P}_{14}\right)$ was accepted.

Secondly, the research finding revealed that the technical service has a significant influence on tourist satisfaction towards ETS $(\beta=0.408, t=6.394, p<0.05$, CI [0.217, 0.293]). According to Tripathi and Borrion (2016), the punctuality of the train is the main measurement of technical service quality. Delayed train arrival or departure will affect passengers' satisfaction and thus their behavioural intention (Olsson, 2020). Studies have also stated that long waiting period can influence passengers' perception as it leads to negative feelings such as anger, anxiety and frustration (Palmqvist, 2019). Besides that, previous literature has also strongly related technical service quality to the efficiency of the ticketing operation system. The application of technology-based e-ticketing system enhances passengers' expectation towards trouble-free, adequate and ease of use ticketing system. Previous literature has consistently demonstrated that the technical service quality is a vital factor in predicting passengers' satisfaction and loyalty towards railway transportation (Yilmaz and Ari, 2016; Vu et al., 2020). Herewith, Hypothesis $2\left(\mathrm{P}_{24}\right)$ was accepted. Thirdly, analysis of safety construct indicated a significant influence on tourist 
satisfaction towards ETS $(\beta=0.307, \mathrm{t}=8.275, \mathrm{p}<0.05, \mathrm{CI}[0.311,0.504])$. According to Hernik and Mazur (2018), besides the service quality, the other important element in creating passenger satisfaction towards public transport is safety. Mat et al. (2019) agreed that security and safety in public transportation specifically in railway transportation is essential due to the increasing number of crimes. Women are potentially exposed to being victims of a crime. Thus, the service provider needs to enhance the security system at the railway station, parking area and onboard the train throughout the entire journey. Similarly, Shen et al. (2016) demonstrated that safety and security were the most important factors affecting the passengers' perception of using the urban rail transit in Suzhou. Mat et al. (2019) also revealed that safety is significantly related to passenger satisfaction towards ETS. Thus, Hypothesis $3\left(\mathrm{P}_{34}\right)$ was also accepted.

Lastly, tourist satisfaction was identified to significantly influence tourist loyalty towards ETS $(\beta=0.727, \mathrm{t}=23.835, \mathrm{p}<0.05$, CI [0.665, 0.784]). According to Wang et al. (2020), the primary component to develop customer satisfaction is the quality of service provided. A study by de Oña et al. (2016) revealed that positive customer satisfaction directly influences customer reuse intention. Furthermore, customer satisfaction towards the quality service of railway transportation can positively and significantly affect customers' behavioural intention of travelling by train. Yilmaz and Ari (2016) proved that passengers' satisfaction on high-speed rail in Turkey has enhanced their loyalty. Meanwhile, Wang et al. (2020) also revealed that customer satisfaction can positively affect their reuse intention towards urban rail transit in Tianjin, China. Moreover, Bahtiar and Zaini (2014) posited that the greater the service quality, the greater the passengers' satisfaction leading to their loyalty. Hence, Hypothesis $4\left(\mathrm{P}_{45}\right)$ was also accepted. Table 5 summarises the outcome for the research hypotheses delineating the path of coefficient significance levels between constructs.

Table 5 A summary of significant evaluation and construct relevance

\begin{tabular}{lccccccc}
\hline Hypo & Path & Relationship & $\beta$ & $t$ & $P$ & $95 \%$ CI & Results \\
\hline H1 & $\mathrm{P}_{14}$ & FSQ -> satisfaction & 0.198 & 4.102 & $0.000^{*}$ & {$[0.104,0.293]$} & Accepted \\
H2 & $\mathrm{P}_{24}$ & TSQ -> satisfaction & 0.408 & 6.394 & $0.000^{*}$ & {$[0.217,0.293]$} & Accepted \\
H3 & $\mathrm{P}_{34}$ & Safety -> satisfaction & 0.307 & 8.275 & $0.000^{*}$ & {$[0.311,0.504]$} & Accepted \\
H4 & $\mathrm{P}_{45}$ & Satisfaction -> loyalty & 0.727 & 23.835 & $0.000^{*}$ & {$[0.665,0.784]$} & Accepted \\
\hline
\end{tabular}

Notes: * Significant $\mathrm{p}<0.05$

\subsection{Coefficient of determination $\left(R^{2}\right)$}

The assessment of $\mathrm{R}^{2}$ is a major part of structural model evaluation. The $\mathrm{R}^{2}$ evaluate the structural model by measuring the model's predictive accuracy. To describe whether the $\mathrm{R}^{2}$ has a weak, medium or strong coefficient of determination, the values $0.25,0.5$ and 0.7 were used as thresholds, respectively (Hair et al., 2014; Garson, 2016). The analysis revealed that the three exogenous constructs namely functional service quality, technical service quality and safety can jointly influence $62.4 \%\left(\mathrm{R}^{2}=0.624\right)$ of the variance of the endogenous construct tourist satisfaction. Moreover, tourist satisfaction contributed to $52.9 \%\left(\mathrm{R}^{2}=0.529\right)$ of the variance for the endogenous construct of tourist loyalty. All the exogenous constructs demonstrated medium to strong $\mathrm{R}^{2}$ value on the endogenous 
constructs respectively. Figure 2 is a structural model which illustrates the effects of exogenous constructs on endogenous constructs.

Figure 2 Structural model

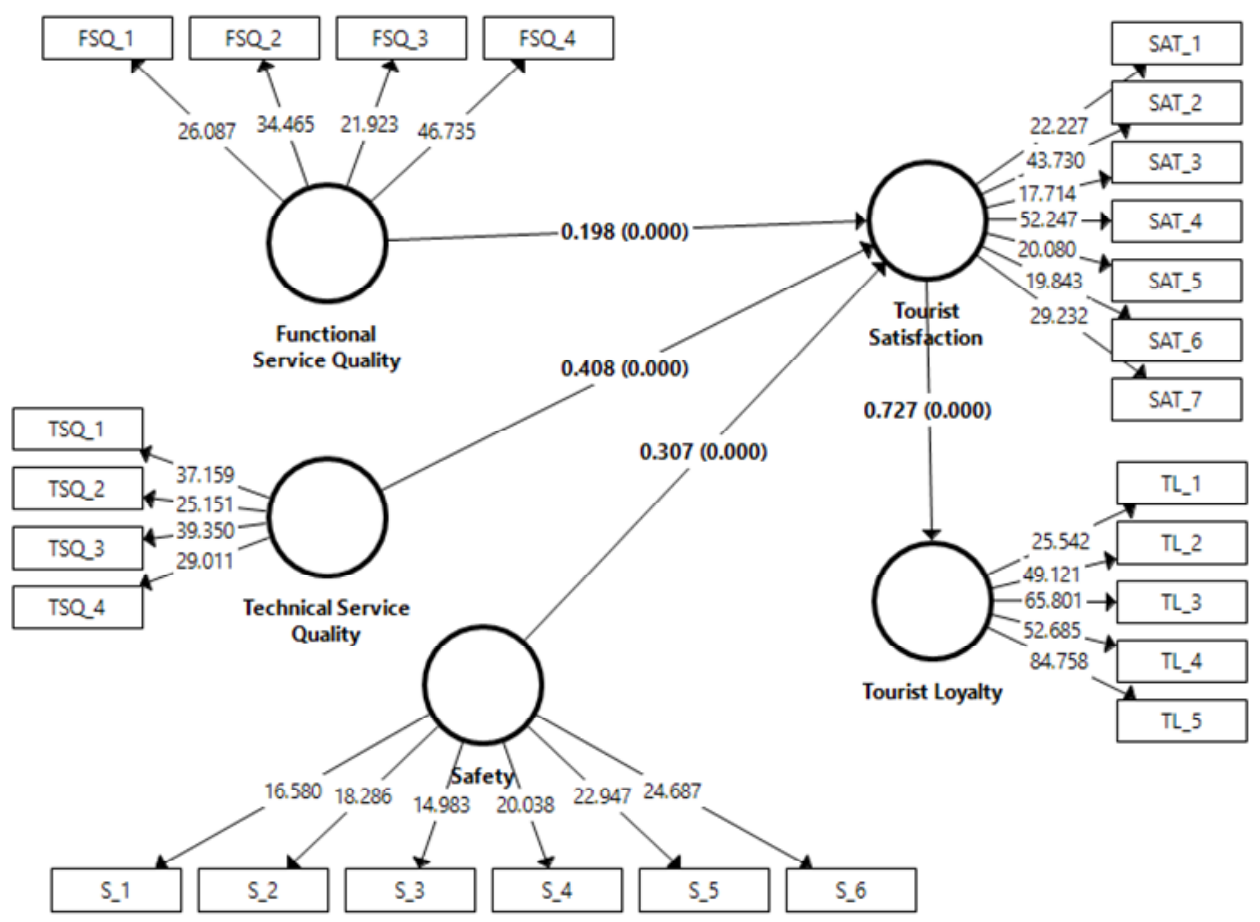

\section{Discussion}

This study aimed to identify the key dimensions of service quality that could lead to tourist loyalty towards ETS. The structural model using PLS-SEM analysis revealed that the service quality can be conceptualised as functional service quality, technical service quality and safety. The validation test of discriminant and convergent in reflective measurement model evaluation indicated that the proposed three dimensions of service quality yielded appropriate reliability and validity. The empirical results generated in this study also supported the proposed conceptual model which provided service quality, apart from positively explaining and predicting tourist satisfaction and their loyalty towards ETS. The statistical findings also indicated that functional service, technical service, safety and tourist satisfaction were significant predictor in explaining tourist loyalty towards ETS. Among the three dimensions, safety was identified as the most important variable. These variables in actuality are associated with tourist decision making in choosing public transport to reach tourism destination (Murugan, 2020). Apart from the speed aspect, train travel is preferred by people due to its safety features and convenience to reach their destination compared to that of express buses which are often involved in fatal road accidents, and are often inconvenient and late (The Star, 2013; Hernik and Mazur, 2018). The next important constructs are technical service quality and 
functional service quality. Having said that, ETS is a popular mode of transport among tourists due to their punctuality because the train departs and arrives at the scheduled time. Besides that, it is also more preferred due to its efficient e-ticketing system, convenience, comfortable facilities together with an effective security and safety system. Hence, the greater quality of service provided on the train and at the railway station could enhance tourists' satisfaction and their loyalty towards ETS.

\section{Conclusions}

In conclusion, the research findings provided numerous significant implications on both theoretical and managerial aspects. This study contributed significant additions to the existing body of knowledge, particularly on that of hospitality and tourism management. Limited studies focused on ETS specifically concerning the service quality and customer loyalty. To fill this gap, this research mainly focused on tourist loyalty towards ETS by understanding their perception on the service quality through the measurement of functional service quality, technical service quality and safety. The multivariate technique analysis PLS-SEM generated the conceptual model to refine the interrelationship between constructs. Undoubtedly, the conceptual model can be expanded to other studies related to ETS or high-speed rail transport from other countries. The information obtained also provided practical implications for the authorities and operator of ETS, including KTMB, Tourism Malaysia, MOTAC and Ministry of Transport Malaysia (MOT) regarding the service quality factors that need to be fully considered in highlighting ETS as the most popular public transport among tourists. Moreover, due to the COVID-19 pandemic outbreak, it is vital to implement standard sanitary procedures at all facilities at railway stations and on board the train in order to gain customer's trust.

This study also has several limitations. First, the research findings revealed that functional service quality, technical service quality and safety only explained $62.4 \%$ of the variance on tourist satisfaction towards ETS. This data indicated that $37.6 \%$ of variance points to other factors. Hence, future research could investigate other potential factors that can enhance tourist satisfaction thus their loyalty, such as reliability, convenience, ambience and corporate image (Yilmaz and Ari, 2016; Willy et al., 2018; Mat et al., 2019). Secondly, the data collection process was conducted during COVID-19 pandemic outbreak disease. Consequently, the limited number of respondents consisting of international tourists could have been due to the government's international travel restriction. Therefore, further studies could include equal numbers of local and international tourists to generalise the findings. Thirdly, this study only focused on passengers of ETS who received the service during their journey to and fro Kuala Lumpur to Northern destination of Malaysia. Future research may explore the different scope of the study by covering all ETS destinations. Fourthly, the future study can employ multilevel structural equation modelling (MSEM) technique analysis as it is expected to produce more robust and detailed findings. 


\section{References}

Anjali, R.V. and Prita, D.M. (2018) 'A review of dimensions of tourism transport affecting tourist satisfaction', Indian Journal of Commerce and Management Studies, Vol. 9, No. 1, pp.72-80.

Bahtiar, A.Z. and Zaini, N.H. (2014) Relationships between service quality, customer satisfaction and customer loyalty towards the introduction of commuter pink coach (KTMB)', in National Action Research Conference (NARC), Melaka.

Basari, M.A.M.D. and Shamsudin, M.F. (2020) 'Does customer satisfaction matters?', Journal of Undergraduate Social Science and Technology, Vol. 2, No. 1, pp.1-15.

Cavana, R.Y., Corbett, L.M. and Lo, Y.L. (2007) 'Developing zones of tolerance for managing passenger rail service quality', International Journal of Quality and Reliability Management, Vol. 24, No. 1, pp.7-31.

Čičmancová, S. (2013) 'Safety of railway system commuter rail in Norway', Transportation Letters, Vol. 12, No. 4, pp.288-292.

de Oña, J., de Oña, R., Eboli, L., Forciniti, C. and Mazzulla, G. (2016) 'Transit passengers' behavioural intentions: the influence of service quality and customer satisfaction', Transportmetrica A: Transport Science, Vol. 12, No. 5, pp.385-412.

Faizan, A., Kashif, H., Rupam, K. and Jeon, H.M. (2017) 'The effect of technical and functional quality on guests' perceived hotel service quality and satisfaction: a SEM-PLS analysis', Journal of Quality Assurance in Hospitality and Tourism, Vol. 18, No. 3, pp.354-378.

Fu, Y., Eboli, L., Mazzulla, G. and Zhang, Y. (2017) 'Railway service quality in northern Italy: a multilevel synthetic assessment', Advances in Mechanical Engineering. Vol. 9, DOI: 10.1177/ 1687814016686317.

Garson, G.D. (2016) Partial Least Squares: Regression and Structural Equation Models, 6th ed., Statistical Associates Publishing, Asheboro.

Geetika, G. and Shefali, N. (2010) 'Determinants of customer satisfaction on service quality: a study of railway platforms in India', Journal of Public Transportation, Vol. 13, No. 1, pp.97-113.

Ghosal, S., Chaturvedi, S., Taywade, A. and Jaisankar, N. (2015) 'Android application for ticket booking and ticket checking in suburban railways', Indian Journal of Science and Technology, Vol. 8, No. S2, pp.171-178.

Görçün, Ö.F. (2018) 'Impacts of high-speed trains on tourism development: a case study of Ankara-Konya high speed rail lines', Journal of Tourism Theory and Research, Vol. 4, No. 1, pp.21-28.

Hair, J.F., Black, W.C., Babin, B.J. Anderson, R.E. and Tatham, R.L. (2006) Multivariate Data Analysis, 6th ed., Pearson University Press, Upper Saddle River, NJ.

Hair, J.F., Hult, G.T.M., Ringle, C.M. and Sarstedt, M. (2014) A Primer on Partial Least Squares Structural Equation Modeling (PLS-SEM), SAGE, California.

Hamid, N.A., Tan, P.L., Zali, M.F.M., Rahamat, N. and Aziz, N.A. (2015) 'Safety and security needs of commuter rail services-travellers' perceptions', Journal of the Eastern Asia Society for Transportation Studies, Vol. 11, No. 1, pp.1495-1506.

Hashim, N.I., Fauzi, N.M., Zan, U.M.S. and Shahar, W.S.S. (2019) 'An overview of public transportation services as an attraction of tourism industry in Malaysia', Proceeding of the 6th International Conference on Management and Muamalah 2019 (ICoMM 2019), e-ISBN: 978-967-2122-74-6.

Hernik, J. and Mazur, R. (2018) 'Innovations and safety in passenger railway transport - the travelers' perspectives', in 33rd International Scientific Conference on Economic and Social Development-Managerial Issues in Modern Business, Warsaw, 26-27 September 2018.

Ibrahim, A.N.H., Borhan, M.N., Yusoff, N.M., and Ismail, A. (2020) 'Rail-based public transport service quality and user satisfaction - a literature', Promet-Traffic and Transportation, Vol. 32, No. 3, pp.423-435. 
Isikli, E., Aydin, N., Celik, E. and Gumus, A.T. (2017) 'Identifying key factors of rail transit service quality: an empirical analysis for Istanbul', Journal of Public Transportation, Vol. 20, No. 1, pp.63-90.

Karim, S., Khan, S., Qureshi, A. and Daud, I. (2012) 'Turning need into demand for Wi-Fi broadband internet access on trains', International Journal of Computer Applications, Vol. 53, No. 4, pp.29-42.

Kim, J.W., Lee, F. and Suh, Y.G. (2015) 'Satisfaction and loyalty from shopping mall experience and brand personality', Service Marketing Quarterly, Vol. 36, No. 1, pp.62-76.

KTMB History (2018) [online] https://www.ktmb.com.my/ (accessed 5 January 2021).

Kukanja, M. and Planinc, T. (2020) 'Service quality in restaurants operating in a rural area: the case of Slovenian Istria', Academica Turistica, Vol. 147, No. 2, pp.147-159.

Machado-Leon, J.L., de Ona, R., Baouni, T. and de Ona, J. (2017) 'Railway transit services in Algiers: priority improvement actions based on users perceptions', Transport Policy, Vol. 53, No. 1, pp.175-185.

Masirin, M.I.M, Salin, A.M., Zainorabidin, A., Martin, D. and Samsudin, N. (2017) 'Review on Malaysian rail transit operation and management system: issues and solution in integration', International Research and Innovation Summit, DOI: 10.1088/1757-899X/226/1/012029.

Mat, A., Bahry, N.S., Kori, N.L., Munir, Z.A. and Daud, N.M. (2019) 'The influence of service quality and passenger satisfaction towards electric train services (ETS): a PLS-SEM approach', Foundation of Management, Vol. 11, No. 1, pp.57-64.

Mgiba, F.M. and Madela, K. (2020) 'South African fuel industry, customer perceptions and satisfaction and their impact on customer loyalty and repurchase intention', Journal of Contemporary Management, Vol. 17, No. 1, pp.16-40.

Mohamad, N. (2020) 'Understanding the influence of media richness in developing customer trust, commitment and loyalty', Journal of Business and Social Development, Vol. 8, No. 2, pp.25-36.

Morgan, R.M. and Hunt, S.D. (1994) 'The commitment-trust theory of relationship marketing', Journal of Marketing, Vol. 58, No. 3, pp.20-38.

Murugan, B.M. (2020) 'A study on passenger satisfaction towards rail service in Indian railways', Studies in Indian Place Names, Vol. 40, No. 50, pp.4282-4287.

Najafipour, A.A., Fallah, Y.A., Foroozanfar, M.H., Adib, Z. and Morteza, S. (2019) 'Developing a model for tourism smart card and evaluating its effect on tourism services', Turizam: Međunarodni Znanstveno-Stručni Časopis, Vol. 67, No. 2, pp.147-158.

Nasrul, N. (2020) 'The effect of functional quality variables and technical quality on patient satisfaction mediated by image', Management Science Letters, Vol. 10, No. 7, pp.1587-1596.

Nordin, N., Masirin, M.I.M., Ghazali, M.I. and Azis, M.I. (2017) 'Appraisal on rail transit development: a review on train services and safety', in IOP Conference Series: Materials Science and Engineering, Vol. 226, No. 1, DOI: 10.1088/1757-899X/226/1/012034\.

Ojo, T.K., Nutsogbodo, R.Y., Appiah-Mintah, R. (2014) 'Passenger's perspective of quality of intercity bus transport service on Accra-Cape coast route, Ghana', GE International Journal of Management Research, Vol. 2, No. 7, pp.267-287.

Olsson, N.O.E. (2020) 'Train punctuality analysis in a rolling stock perspective', Transportation Research Procedia, Vol. 47, No. 1, pp.641-647.

Oyedele, O.A. (2018) 'Sustainable railway station facilities management in developing nations', International Journal of Sociology and Anthropology, Vol. 3, No. 8, pp.290-294.

Palmqvist, C.W. (2019) 'Delays and Timetabling for Passenger Trains', Unpublished doctoral dissertation, Lund University.

Parasuraman, A., Zeithaml, V. and Berry, L. (1988) 'SERVQUAL: a multiple item scale for measuring consumer perceptions of service quality', Journal of Retailing, Vol. 16, No. 1, pp.12-37. 
Putri, Y.A., Wahab, W. and Shihab, M.S. (2018) 'The effect of service quality and brand trust on loyalty and the intervening role of customer satisfaction in transportation service', International Journal of Scientific and Research Publications, Vol. 8, No. 7, pp.369-376.

Ramya, M.N., Kowsalya, A. and Dharanipriya, K. (2019) 'Service quality and its dimensions', International Journal of Quality and Reliability Management, Vol. 4, No. 2, pp.1-29.

Sahrir, A.A., Rozilah, K. and Mohd Idrus, M.M. (2018) 'Railway development and the impact to Malaysian economy', Journal of Advance Research in Dynamical and Control Systems, Vol. 10, No. 6, pp.272-280.

Shen, W., Xiao, W. and Wang, X. (2016) 'Passenger satisfaction evaluation model for Urban rail transit: a structural equation modeling based on partial least squares', Transport Policy, Vol. 46, No. 1, pp.20-31.

Shiaw, T.H., Wan Hashim, W.I., May, C.L. and Yau, S.M. (2019) 'Factors affecting satisfaction and loyalty in public transport using partial least squares structural equation modeling (PLS-SEM)', International Journal of Innovative Technology and Exploring Engineering, Vol. 8, No. 12, pp.569-575.

Sulphey, M.M. and George, S. (2017) 'A study on the relationship between customer satisfaction, business ethics and certain related variables', Journal of Applied Management and Investments, Vol. 6, No. 1, pp.67-75.

The Star (2013) 'Comfort and safety features among reasons why passengers like ETS', The Star Online, 19 August [online] https://www.thestar.com.my/ (accessed 3 February 2021).

The Star (2019) 'Tourism contributes RM42bil to economy', The Star Online, 24 August [online] https://www.thestar.com.my/ (accessed 15 December 2020).

Tourism Malaysia (2020) Tourism contributes RM86.14 billion to Malaysia economy with 26.1 million tourists in 2019 [online] https://tourism.gov.my/media (accessed 8 January 2021).

Tripathi, K. and Borrion, H. (2016) 'Safe, secure or punctual? A simulator study of train driver response to reports of explosives on a metro train', Security Journal, Vol. 29, No. 1, pp.87-105.

Vu, N.T., Dung, H.T., van Dat, N., Duc, P.M., Hung, N.T. and Phuong, N.T.T. (2020) 'Cultural contact and service quality components impact on tourist satisfaction', Journal of Southwest Jiaotong University, Vol. 55, No. 1, pp.1-10.

Wang, Y., Zhang, Z., Zhu, M. and Wang, H. (2020) 'The impact of service quality and customer satisfaction on reuse intention in urban rail transit in Tianjin, China', SAGE Open, January-March, Vol. 10, pp.1-10.

Willy, K., Nunung, N.H., and Septiana, D. R. (2018) 'Passenger satisfaction with railway station service quality: an ordinal logistic regression approach', MATEC Web of Conference, Vol. 181, No. 07001, pp.1-7.

Yilmaz, V. and Ari, E. (2016) 'The effects of service quality, image and customer satisfaction on customer complaints and loyalty in high-speed rail service in Turkey: a proposal of the structural equation model', Transportmetrica A: Transport Science, Vol. 13, No. 1, pp.67-90.

Yusoff, H.M., Safian, E.E.M., Bilal, K. and Yassin, A.M. (2019) 'The criteria of railway station in Malaysia: a review of issues in facilities improvement', Sci. Int. (Lahore), Vol. 31, No. 2, pp.283-287.

Zakaria, Z., Hussin, Z.H., Batau, M.F.A., Zakaria, Z. (2010) 'Service quality of Malaysia public transports: a case study of Malaysia', Cross-Cultural Communication, Vol. 6, No. 2, pp.84-92. 